Santa Clara University

Scholar Commons

Management

Leavey School of Business

$6-2003$

\title{
Virtualness and knowledge in teams: Managing the love triangle of organizations, individuals, and information technology
}

Terri L. Griffith

Santa Clara University, tgriffith@scu.edu

John E. Sawyer

Margaret A. Neale

Follow this and additional works at: http://scholarcommons.scu.edu/mgmt

Part of the Business Administration, Management, and Operations Commons

\section{Recommended Citation}

Griffith, T.L., Sawyer, J.E., \& Neale, M.A. (2003). Virtualness and knowledge: Managing the love triangle of organizations, individuals, and information technology. MIS Quarterly, 27, 265-287.

Copyright (C 2003 by the Management Information Systems Research Center (MISRC) of the University of Minnesota.

This Article is brought to you for free and open access by the Leavey School of Business at Scholar Commons. It has been accepted for inclusion in Management by an authorized administrator of Scholar Commons. For more information, please contact rscroggin@scu.edu. 


\section{VIRTUALNESS AND KNOWLEDgE IN TEAMS:}

MANAGING THE LOVE TRIANGLE OF

ORGANIZATIONS, INDIVIDUALS, AND

INFORMATION TECHNOLOGY ${ }^{1}$

By: Terri L. Griffith

Leavey School of Business

Santa Clara University

St. Joseph's Hall \#116

Santa Clara, CA 95053

U.S.A.

tgriffith@scu.edu

John E. Sawyer

Department of Business Administration

Alfred Lerner College of Business \&

Economics

University of Delaware

237 MBNA America Hall

Newark, DE 19716

U.S.A.

sawyerj@lerner.udel.edu

Margaret A. Neale

Graduate School of Business

Stanford University

Stanford, CA 94305

U.S.A.

neale_margaret@gsb.stanford.edu

${ }^{1}$ Robert W. Zmud was the accepting senior editor for this paper.

\begin{abstract}
Information technology can facilitate the dissemination of knowledge across the organizationeven to the point of making virtual teams a viable alternative to face-to-face work. However, unless managed, the combination of information technology and virtual work may serve to change the distribution of different types of knowledge across individuals, teams, and the organization. Implications include the possibility that information technology plays the role of a jealous mistress when it comes to the development and ownership of valuable knowledge in organizations; that is, information technology may destabilize the relationship between organizations and their employees when it comes to the transfer of knowledge. The paper advances theory and informs practice by illustrating the dynamics of knowledge development and transfer in more and less virtual teams.
\end{abstract}

Keywords: Group dynamics, organizational learning, knowledge acquisition, knowledge utilization, distributed work arrangements

ISRL Categories: AA09, ACO303, AL04, DD06, GA0501 


\section{Introduction}

Organizations are under constant pressure to create synergies in the resources under their control. Teams and knowledge management are two areas that are often fruitful in providing increased value when carefully managed. Teams can increase capability, flexibility, and responsiveness (for a review, see Leavitt 1996), while knowledge management is believed to be crucial to organizational performance (Berman et al. 2002; Kogut and Zander 1992; Liebeskind 1996).

Technology often plays a supporting role in this work. For example, "LotusNotes....and Vision Quest help us to work in a more organized fashion as a team and be more productive" (participant 11504 in DeSanctis et al. 2000, p. 2). Technology may provide a means of structuring teamwork, enhance the information available to the team, and/or provide a communication system (McGrath and Berdahl 1998). Technology may "informate" the work process, creating information where it did not exist before (Zuboff 1988, p. 10). That is, technology may go beyond mere automation of the task, for example, by providing an information stream about the task and its interrelationships.

Technology may also expand the opportunities for teams to be effective. The growth of virtual teams in organizations is the example on which we will focus here. Organizations can form teams regardless of the physical location of the members, providing further opportunity and flexibility in building the best teams (e.g., Griffith and Neale 2001). Organizations can also take advantage of the ability of such teams to work around the clock by locating team members in time zones spanning the globe. Almost one-third of a sample of Fortune 500 firms has some form of virtual work in place (Davenport and Pearlson 1998).

We believe there is additional opportunity in considering virtual teams and knowledge management in tandem. More and less virtual teams use technology in ways that capture more and less knowledge for the organization. Modern organizational teams have access to a variety of communication and work process technologies. These range from e-mail and voice mail to broad-based enterprise solutions such as SAP. More virtual teams seem to use technology to do their work as a matter of course, passively collecting knowledge and perhaps sidestepping many of the motivational problems of knowledge management (e.g., Goodman and Darr 1998) found in more traditional settings. Equivalent levels of knowledge capture in less virtual teams might require added work. The added work, even the straightforward task of documentation, may cause such efforts to fail, regardless of the benefit of knowledge management (Goodman and Darr 1998; Majchrzak et al. 2000).

There may also be negative effects related to virtual teams and knowledge. If the perspective is that of increasing value to the organization, our analysis seems to suggest that the use of more virtual teams provides an opportunity for knowledge capture to occur at a low marginal cost. However, individuals who hold this knowledge to be captured may experience a considerable loss even as the organization gains.

The discussion below will assess the dynamics between the individual, the organization, and information technology in the context of teams that vary in their virtualness. First we address the role communication and information technologies play in the form and function of teams. We then make the critical link between types of knowledge and knowledge transfer in more and less virtual teams. Finally, implications are considered, including the possibility that information technology may play the role of a jealous mistress when it comes to the development and ownership of valuable knowledge in organizations; that is, information technology may destabilize the relationship between organizations and their employees when it comes to the transfer of knowledge.

\section{Knowledge and Virtualness in Teams}

\section{Context: Virtualness and Knowledge}

Team context and technological support are key to our analysis. Technology enables these variations in context in two ways. First, communication 


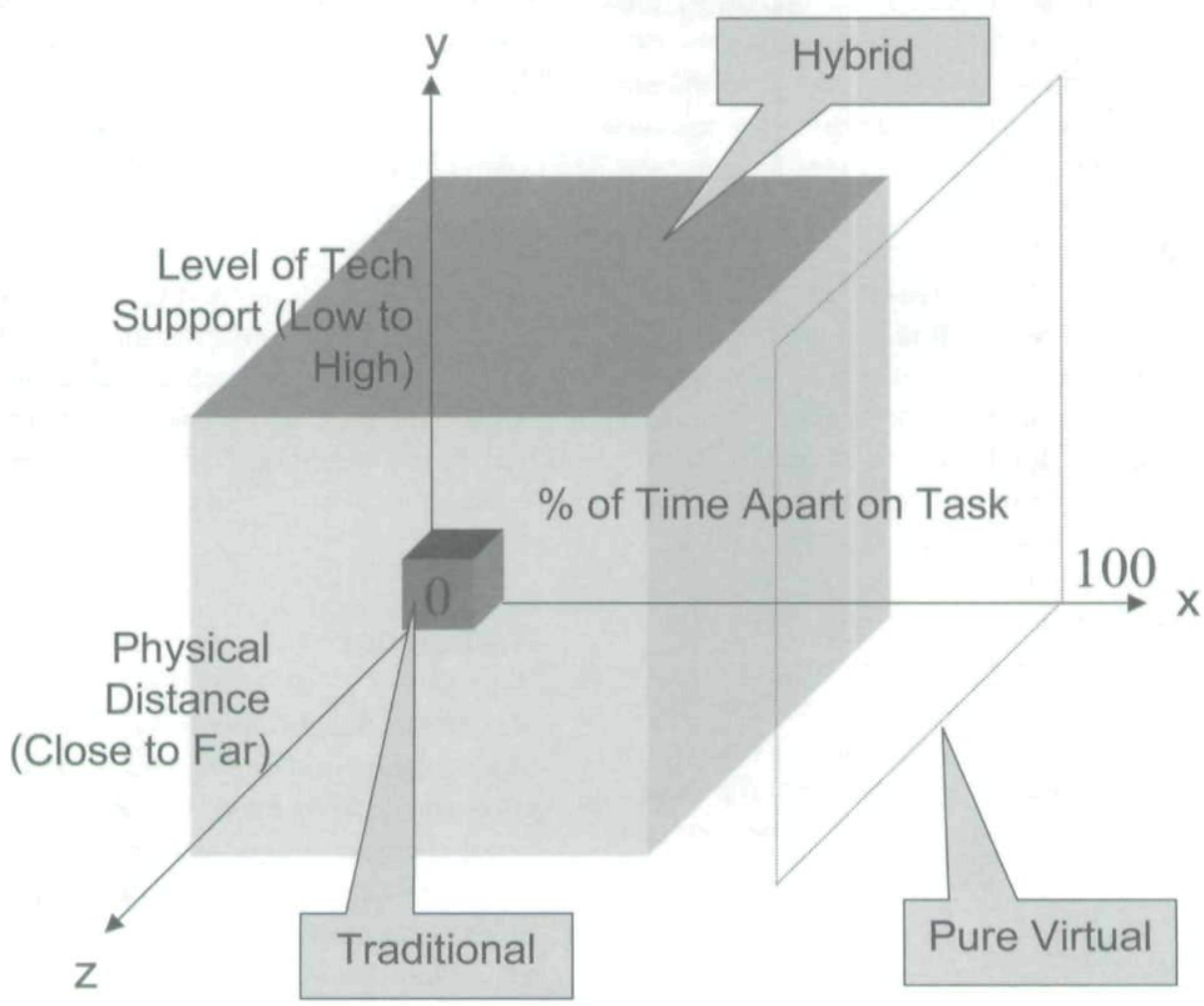

\section{Figure 1. Dimensions of Virtualness}

technology (such as e-mail, voice mail, etc.) makes it feasible for work teams to be formed with members who do not necessarily work in close proximity. The reduction in physical and temporal boundaries subsequently diminishes the likelihood that homogenous teams are formed for convenience, or due to other factors that might collocate members in either space or time (Griffith and Neale 2001). In addition, group support technology (such as GroupSystems ${ }^{\mathrm{TM}}$ or LotusNotes ${ }^{\mathrm{TM}}$ ) may provide additional functionality by structuring the team's tasks, enabling analysis of the team's process, and/or the storage of the team's information.

Clearly the functionality of such technologies is mutable and socially constructed (Barley 1986; DeSanctis and Poole 1994; Griffith 1999). Dif- ferent configurations may provide communication and/or support (Griffith and Northcraft 1994) and teams may choose to appropriate different technology features, or not. As a result, we will speak in terms of more or less virtual rather than technological, physical, or temporal structures. Figure 1 provides a graphic description showing the full range of work team possibilities.

We propose three distinct team categories: traditional, hybrid, and pure virtual. The $y$-axis represents the level of technological support used by the team. Technological support (either electronic or otherwise) may include communication, documentation, and/or decision support capability. The $\mathrm{x}$-axis represents the percentage of work that the team does with its members distributed across time or space. The z-axis represents the distri- 
bution of the physical locations occupied by the team members. ${ }^{2}$ Note that pure virtual teams take up the plane depicted on the far right, regardless of the level of technological support they use. We believe that teams that never meet face-to-face are different in a nonlinear way from teams that do meet (and show this plane as separate to highlight this difference). ${ }^{3}$ Pure face-to-face (traditional) teams form the other extreme and are depicted as the cube at the origin of the graph. These are teams that do all of their work face-to-face, and make no use of technological support. In the current technology environment, pure face-to-face teams may be rare in organizations. Most of today's organizational teams are likely to fall into the large hybrid category of teams composed of members who interact over time, according to the needs of the moment, and through media, with the amount of face-to-face contact determined by their own adaptation and structuration of the process (e.g., DeSanctis and Poole 1994). This space is shown as the large shaded area in Figure 1.

More virtual teams may be able to draw upon a larger network for sources of knowledge due to their expected greater informational diversity (Griffith and Neale 2001). Similarity (e.g., Ancona and Caldwell 1992), proximity (e.g., Festinger et al. 1950), and prior acquaintance (e.g., Goins and Mannix 1999) are all factors that may bring particular members into a team. However, such forces serve to reduce potential team knowledge as the knowledge and perspective of team members drawn from similar social networks are likely to be redundant (Granovetter 1973). We believe that virtual teams are more likely to be derived from less similar members than are more traditional teams. In fact, virtual teams are likely to be formed when needed skills are not available locally (Boutellier et al. 1998), suggesting that more virtual teams are less likely to be drawn from

\footnotetext{
${ }^{2}$ An empirical calculation of this distribution can by created using the entropy approach (Jehn et al. $1999 \mathrm{p}$. 749; Teachman 1980).

${ }^{3}$ Please note that our inclusion of the possibility of pure virtual teams that make no use of technology is founded on our inability to exclude such teams on a theoretical basis.
}

similar social networks. As a result, we assume members of virtual teams will have access to a potentially greater base of knowledge through their individual team members than collocated teams. ${ }^{4}$ Further, as teams differ in their amount of virtualness, so too do they differ in critical ways regarding the transfer of knowledge from their members to the team and to the organization. In the section below, we present a model of knowledge transfer and highlight the areas where virtualness may play a role in how knowledge is transferred among individuals, to the team, and the organization.

\section{Knowledge in Organizations}

The scientific understanding of knowledge in organizations is still in an infant stage in spite of a large and growing literature focused on organizational knowledge, organizational learning, knowledge creation, and knowledge management. Beyond common concepts such as tacit knowledge and organizational knowledge, the many theoretical frameworks offer diverse concepts, terminology, hypotheses, and evidence (Nonaka and Nishiguchi 2001).

A thorough review of the knowledge literature is beyond the scope of this manuscript. We wish to focus on the distinction between individual and social knowledge for differing types of knowledge development in the context of virtual teams. Individual knowledge is composed of the psychological components that reside within the individual. Social knowledge is a collective type of knowledge that is publicly available or embedded within the routines, culture, or norms of the team (Spender 1996). A group's repertoire of decisionmaking approaches is an example of such social knowledge. We detail the components of individual and social knowledge below as we focus on

\footnotetext{
${ }^{4}$ This assumption is based on both theoretical (Griffith and Neale 2001) and field based (Boutellier et al. 1998; Orlikowski 2002) foundations.
} 


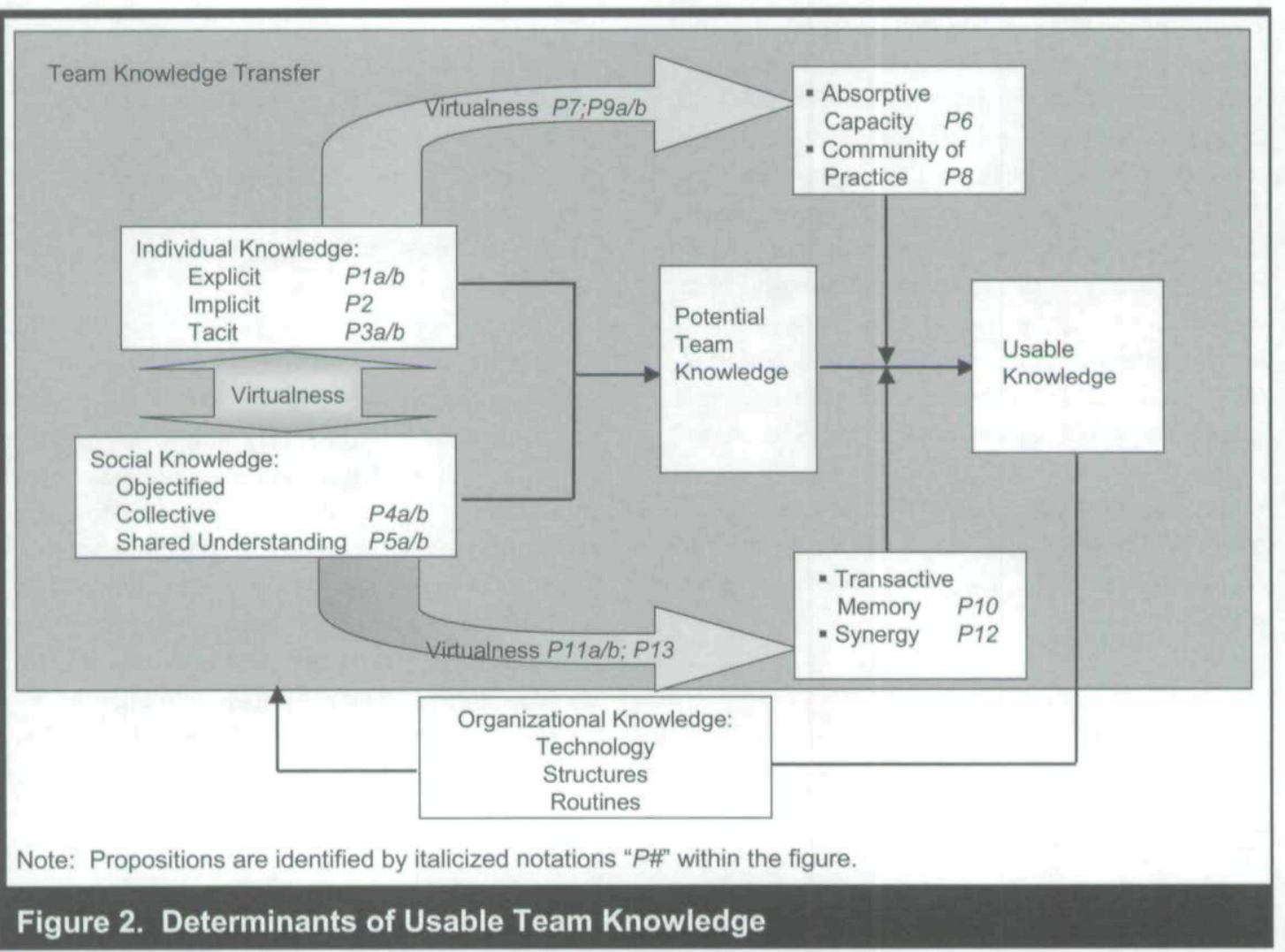

how knowledge transfers among individuals and becomes available to the team. Figure 2 provides a stylized model of this transformation.

This model is presented from a perspective of virtual teams where membership is relatively stable, but with members having interaction both within the focal team, as well as with collocated others. We leave the possibility of teams with more fluid membership (e.g., Gruenfeld et al. 2000) for future consideration. The propositions will be stated in terms of more and less virtual. This allows for consideration of more virtual teams that spend little time on task together, use a great deal of technology for their communication and work, and are geographically distributed, as well as slightly less virtual teams that might have more face to face interaction, or subgroups (some collocated members), and less virtual teams with greater amounts of face-to-face interaction, more collocated members, and less dependence on technology for communication and work.

\section{Knowledge and its Transfer In Virtual Teams}

In the next sections, we will use Figure 2 as a road map for examining different types of knowledge; the moderating effects of absorptive capacity, communities of practice, transactive memory, and synergy; and the recursive link from the resulting usable knowledge. We use the term usable knowledge here to reflect the notion that while knowledge may exist within the team (potential team knowledge), it is not usable unless the team possesses the necessary tacit knowledge, both at 
the individual and social level, to know when and how to use that knowledge. This model is largely drawn from extant literature, as we will point out as we discuss the model, and is intended to reflect how knowledge comes to and is used by the team. Our contribution is in combining the results from the prior literature in a way that is amenable to an assessment of the opportunities and challenges presented by considering more and less virtual teams from the perspective of knowledge. We believe that the virtualness of teams plays a role where potential team knowledge is (or is not) transformed into usable knowledge. Individual absorptive capacity, communities of practice, transactive memory, and synergy are all affected by the team context, e.g., the virtualness of the team.

\section{Individual Knowledge Types}

In Figure 2, we begin by recognizing that knowledge is embedded in individuals, the social context, and the organization. Individual knowledge is conceptualized as a continuum from explicit to tacit.

Hard distinctions between tacit and explicit knowledge are more often a convenience than a theoretical requirement. Some knowledge will seem to be a particularly clear example of tacit, some of explicit, while other knowledge will seem to share elements of both tacit and explicit. Polanyi (1966) pointed out that tacit knowledge cannot be articulated. Spender (1996) further clarified that some tacit knowledge could be articulated but has yet to be so, while other tacit knowledge is incapable of being articulated. Explicit knowledge can be articulated and is, thus, accessible to others (Leonard and Sensiper 1998).

Leonard and Sensiper suggest that instead of separate constructs, tacit and explicit may signify a continuum, noting that Polanyi's discussion allows that all knowledge has tacit dimensions. Thus, we consider these forms of individual knowing as ranges along a continuum, although they are easier to discuss as discrete points. To simplify the discussion of this continuum we will use the term explicit to refer to the most objective or declarative end of the continuum, implicit to refer to the mid-range of the continuum in which knowledge is not currently declarative but could be made so, and tacit to refer to the extreme end of the knowledge continuum in which knowledge has never been, and could not likely be, made declarative.

As noted above, some knowledge is clearly of one form or another (e.g., tacit, implicit, or explicit), while other knowledge may share elements of some or all three types. An example that seems to include all three elements of the knowledge continuum might be the ability to write a research report. There are explicit guidelines for producing such a document. Most researchers have also developed routines learned through their mentors and coauthors, which are not articulated, but could be with some effort. Finally, there is the ability to "hook" the reader and make a more persuasive argument that seems to be a skill that is developed with experience and is very difficult if not impossible to fully articulate.

Explicit knowledge has been referred to in the literature variously as objective (Schultze 2000), information (Zander and Kogut 1995), or declarative or fact-based (Berry 1987) knowledge. Distinctions along this continuum can be made on the basis of how knowledge is transferred and how it is initially created or acquired. Researchers working on the development of expert systems have acknowledged the difficulty of transferring knowledge (Berry 1987; Gammack and Yong 1985; Olson and Rueter 1987; Swartout and Smoliar 1987). For example, in constructing expert systems, researchers generally consider three types of knowledge: terminological knowledge, domain descriptive knowledge, and problem-solving knowledge (Swartout and Smoliar 1987). They consider terminological and domain knowledge to be relatively explicit, while problemsolving knowledge tends to have more tacit components. They find that problem-solving knowledge is more difficult to transfer than terminological or domain-descriptive knowledge. (This difficulty with transferring more tacit knowledge will be a theme throughout our examination.) 
In an applied sense, explicit knowledge can be captured in e-mail, discussion groups, or knowledge databases, and can be transferred to others within or outside the team. In making a distinction between tacit and explicit knowledge, Berry (1987) uses a three-stage model of learning based on cognitive (learning from instruction or observation), associative (learning from practice), and autonomous (practice to the point that actions occur without thinking) stages. For example, someone could learn how to use a word processor by attending a class where the rules are taught (cognitive), then by working with the word processor to create different kinds of documents (associative), and finally, through extensive practice, reach the stage where typing errors are corrected seemingly without thought, the fingers immediately hitting the right keys (autonomous). In the most extreme form of autonomous learning, it will actually be difficult for the learner to recall exactly what they have done to make the action occur.

Berry suggests that these different stages of learning differentially support the ability to obtain explicit versus tacit knowledge. In the cognitive and associative stages, individuals learn through instruction, observation, and practice. In these stages, explicit knowledge can be effectively transferred in written form, through training programs, and through other media such as databases.

We believe that the virtualness of the work plays a key role in understanding the transfer of knowledge. Teams who spend less time together on task, are located further apart, and who make greater use of technological tools (i.e., more virtual teams) will be more likely to transfer knowledge in explicit rather than tacit forms because the technology supports the declarative nature of explicit knowledge. Tacit knowledge is more "sticky," more difficult to transfer in a usable form (Von Hipple 1994). Members of more virtual teams have a greater need to transform tacit knowledge into more explicit forms if they are to transmit this knowledge to their teammates. For example, Tidwell and Walther (2002) found that subjects who used computer-mediated communi- cation used a more direct communication approach than subjects in face-to-face conditions. We believe that it is also possible that more virtual teams, having made their knowledge more explicit and having used technological tools for communicating this knowledge (e.g., e-mail), will have permanent (and searchable) access to this knowledge. ${ }^{5}$ More virtual teams may also choose technologies with such capabilities over less permanent and searchable tools (e.g., voice mail). It is not that less virtual teams do not use similar tools; rather, it is that more virtual teams are likely to rely more on such systems and so the effect will be more dominant. Consider an experienced team member trying to transfer their best practices regarding customer presentations. In a face-toface setting, this implicit knowledge could be demonstrated. Depending on whether or not the team chose to record the presentation, there might or might not be a record. In a more virtual setting, there might be stronger emphasis on creating a framework or set of rules about giving such presentations (e.g., Tidwell and Walther's finding that computer mediated communication may be more direct). The emphasis on verbalization (versus demonstration) helps to recapture implicit knowledge in an explicit form.

In summary,

Proposition 1a: More virtual teams are more likely to transform implicit knowl-

\footnotetext{
${ }^{5}$ Even the most basic e-mail system can serve as a knowledge management tool. For example, Eudora is a popular e-mail tool available in a freeware form. Sent and received messages can be sorted based on sender, topic, date, etc. The content of the messages can also be searched using the tools provided. These features enable identification of the person providing information on a particular topic, the information itself, or an assessment of response rates and the like. Teams may also adopt strategies to make these tools more effective, such as using keyword subject headings, although this may be difficult to implement (e.g., Majchrzak et al. 2000), and having a single topic per message (as discussed on a Web site for effective e-mail use: http://www.library.yale.edu/training/netiquette/). Such sociotechnical strategies make for easier search and filtering of messages into particular mailboxes. More complex strategies for using e-mail as a knowledge base are also available (e.g., Knowledge Mail $^{\circledR}$ ).
} 
edge into explicit knowledge than are less virtual teams.

\section{Proposition 1b: More virtual teams are more likely to have access to their extant explicit knowledge than are less virtual teams.}

We turn now to a more fine-grained assessment of tacit knowledge. We differentiate implicit from tacit knowledge as a matter of degree. Implicit knowledge refers to knowledge that is made tacit through practice. In the later autonomous stage of learning, explicit knowledge may become tacit as "relationships are compiled through practice to the point where they can be done 'without thinking'" (Berry 1987, p. 145). Thus, as expertise develops, individuals "lose awareness of what they know" (p. 145). However, this is not necessarily a permanent transition.

Research on building expert systems has found that rules, terminology, and descriptions that have been lost through autonomous processing may be recaptured. Once recaptured, this knowledge is capable of being transferred to other individuals in the form of explicit knowledge. Thus, in the virtual team that relies heavily on verbal (word-based, such as telephone or e-mail) forms of communication, implicit knowledge can be captured in relatively explicit forms and transferred to others. Because virtual teams must rely more on technologies, much of which transfers information in verbal modes, these teams may find it more useful to convert and transfer knowledge in explicit forms.

Proposition 2: Implicit knowledge can be transferred to explicit knowledge to the extent that a proactive effort is made to verbalize rules, terminology, and descriptions.

At the opposite end of the knowledge continuum from explicit knowledge is tacit knowledgeknowledge that has been formed through experience and that has never been represented explicitly. With this type of knowledge, experience is necessary for new, tacit knowledge to take shape, as new patterns, associations, and processes are formed. Patterns, if-then relations, and instrumental processes, which cannot be effectively taught through instruction, form through trial-and-error learning (Sawyer 1990, 1991), but once learned often cannot be directly described and, thus, are tacit. Specifically, this type of knowledge has been described as deep tacit knowledge (Leonard and Sensiper 1998).

It is unlikely that such tacit knowledge can be made explicit (Berry 1987). Structured processes fail to transfer the less tangible elements of tacit knowledge (Pfeffer and Sutton 1999) and significant information loss can be experienced when trying to articulate some experientially derived forms of tacit knowledge. According to some, deep tacit knowledge can only be shared among individuals through a network of individuals (Leonard and Sensiper 1998; Venzin et al. 1998). In this case, knowledge does not actually transfer among members of the network. Instead, the network is used to apply the individual knowledge to the task. Others suggest that tacit knowledge is transferred among individuals working closely together through socialization processes such as on-the-job training, apprenticeship, and direct observation (Nonaka 1994). The members of more virtual teams work in an environment where their relationships are more filtered (by communication technologies) and they have fewer direct physical connections with team members. More virtual teams would thus seem to be at an overall disadvantage relative to more traditional teams when it comes to tacit knowledge transfer. In more virtual teams, it is unlikely that the degree of direct interaction possible through electronicallymediated communication would allow the transfer of tacit knowledge.

Proposition 3a: Having acquired tacit knowledge from collocated sources, members of more virtual teams will be less able to transfer this knowledge to their teams than would members of less virtual teams.

Proposition 3b: Individual members of more virtual teams are less likely to 
acquire tacit knowledge from their teammates than are members of less virtual teams.

In summary, individual knowledge lies on a continuum from explicit (declarative) knowledge, through implicit knowledge that may have at one time been transferred explicitly or could be converted to explicit knowledge, to tacit knowledge that is developed through experience and is impossible to fully capture or transfer as explicit knowledge. More virtual teams will be more likely to rely on explicit knowledge and to attempt to convert implicit knowledge to explicit knowledge to facilitate transfer through electronic media. As such, more virtual teams will be more likely to store and have explicit knowledge in searchable and retrievable form, but will have to rely on the individual to apply tacit knowledge given such knowledge is less capable of being transferred within the team. Less virtual teams will rely more on the transfer of implicit and tacit knowledge through socialization processes and through working side-by-side, but may have less access to stored, searchable, and retrievable explicit knowledge, thus relying more on the individual for retrieval of explicit knowledge (see the discussion on transactive memory below).

\section{Social Knowledge Types}

In Figure 2, there is a double-ended arrow between individual knowledge and social knowledge. This arrow reflects two dynamics. First, social knowledge, knowledge which is either objectified (explicit and known among team members, such as the due date for a particular task), collective (explicit knowledge that has been internalized by the team members, such as the steps to take for moving through a particular process), or has formed as a shared understanding among team members (such as the identity of the emergent leader for different parts of the team's task), flows from individual knowledge as team members interact. The flow is affected by the degree of virtualness. Second, as individual members work within the team, their own knowledge is developed and enhanced as individual and team knowledge is combined. This combinatorial process is influenced as well by the degree of team virtualness.

Nonaka (1994) suggested a "spiral of knowledge" (p. 18) in which individuals' explicit and tacit knowledge transform and build upon one another to form social- and organization-level knowledge. Individual-level explicit knowledge becomes objectified knowledge at the social level of analysis, while individual-level tacit knowledge becomes collective knowledge at the social level of analysis (Spender 1996).

Nonaka suggested that interaction among individuals converts knowledge in various ways. Tacit knowledge at the individual level is converted to tacit knowledge at the team level through socialization. Explicit knowledge is combined with other explicit knowledge to form new explicit knowledge. As tacit knowledge is externalized through interactions among individuals it becomes explicit knowledge. Mutual interaction among individuals can have the effect of causing explicit knowledge to be internalized within the team and thus become tacit. This form of tacit team knowledge is what Spender (1996) refers to as collective knowledge.

Collective knowledge is embedded in the team's routines, norms, and culture. Because mutual interaction is necessary for the implicit combination of various elements of explicit knowledge into collective knowledge, anything that reduces the level of interpersonal interaction in the team may impede the development of collective knowledge. Thus, highly virtual teams may not be able to form collective knowledge unless they are able to use highly enriched forms of media, or at least experience their communication as enriched through greater experience with the task, their teammates, and the technology (Carlson and Zmud 1999).

Proposition 4a: More virtual teams will have greater difficulty forming collective knowledge than will less virtual teams. This effect will be moderated by their experienced richness of communication. 
Proposition $4 \mathbf{b}$ : To the extent that collective knowledge is formed in more virtual teams, their collective knowledge is expected to be more accessible via technological tools, than would the collective knowledge of less virtual teams.

In addition to the conversion of explicit knowledge within the team to collective knowledge, there may be a third form of social tacit knowledge. Similar to the process whereby individuals form new tacit knowledge through experience, teams may form new tacit knowledge through collective action. This tacit knowledge forms the basis of shared understanding (Leonard and Sensiper 1998). Shared understanding is the third type of social knowledge identified in Figure 2. Social knowledge may be considered a continuum from objectified knowledge, through collective knowledge, to shared understanding in a manner similar to the continuum of individual knowledge. Greater shared understanding is more likely to develop in tasks where there is a high level of interdependence (Janz et al. 1997). If teams break tasks into less interdependent, additive parts, such interaction may be impeded; thus, limiting the extent to which shared understanding is formed (Hollingshead 2001). Interdependence requires a high level of communication (Tschan and von Cranach 1996). To the extent that the communication technology employed by virtual teams constrains the richness of communication, those teams may break their task into less interdependent pieces as a way of managing their separation. As a result, we expect

Proposition 5a: More virtual teams have a greater likelihood of enacting an independent approach to their tasks and, therefore, are expected to have less shared understanding of these tasks than less virtual teams.

Proposition 5b: Access to and appropriation of tools and structures that support highly interdependent work will moderate this result on shared knowledge.
Organizational knowledge is the final type of knowledge in our model. Here we will briefly define the components of organizational knowledge, but given its position in the model, we will wait to place it in the overall framework until after we have covered usable knowledge.

So far, our discussion of team effects has been independent of the organizational context in which these teams function. Yet, this context can be critical. Argote (1999) and others (Levitt and March 1988; Starbuck and Milliken 1988; Walsh and Ungson 1991) identify various organizational repositories of knowledge and productivityenhancing improvements: individual workers, an organization's technology, and an organization's structures and routines. Argote (1999) provides evidence that each of these repositories is suited for the development, retention, and transfer of different types of knowledge. Individuals are the most effective media for acquiring and storing tacit knowledge; technology, best for explicit knowledge; while structures and routines are most effective for transferring knowledge.

Organizational knowledge provides a basis and context for the development and transfer of individual and social knowledge. The more knowledge is codifiable (in our model, the more explicit individual or objectified social knowledge), the greater the flow of knowledge both vertically and horizontally in the organization (Schulz 2001). Shultz studied interunit knowledge flow by surveying subsidiary leaders about three domains of organizational knowledge. The dependent variables were the volume of knowledge provided by a subunit to other subunits in each of the knowledge domains. Independent variables included exposure to internal and external sources of new experiences, the uniqueness of a unit's experiences compared to peers, the level of codification of knowledge in the domain, and the amount of inflow of knowledge from both peer and supervising units. Schulz found that horizontal inflow of information was positively related to the horizontal outflow of information. Peer groups shared information more readily with peer groups when there was an expectation of information flowing in from peers. Unit autonomy was also 
positively related, and distances to peers negatively related to horizontal flow of information.

An important finding by Schulz was that horizontal knowledge flow consisted mainly of incremental knowledge, while new knowledge tended to flow vertically. Schulz interpreted this finding by suggesting that new knowledge has uncertain relevance. Uncertainty is best resolved centrally where the exposure to remote and different knowledge is greatest. In contrast, horizontal knowledge flow depends on the absorptive capacity of the peer groups to receive and understand the relevance of the knowledge. This is best done with incremental knowledge as peer groups are more likely to share the necessary knowledge to make sense of the incremental knowledge. Organizational knowledge is created through the enactment of knowledge that occurs as peer groups utilize the knowledge available.

\section{Potential Team Knowledge}

In teams, individual knowledge and social knowledge combine to form potential team knowledge. This is the total pool of explicit, implicit, and tacit knowledge residing in the individual members of the team, as well as the objectified, collective, and shared understanding residing as the social knowledge of the team. Potential knowledge is only realized if the individuals within the team, and the team itself, can utilize the potential knowledge. We expect that the level of usable knowledge will be moderated by the absorptive capacity (Cohen and Levinthal 1990) of members of the team, the availability of relevant communities of practice, and the team's transactive memory and synergy. In the next three sections, we will discuss both individual level absorptive capacity and communities of practice, and the two group level phenomenon: transactive memory and synergy.

\section{Absorptive Capacity and Communities of Practice}

Absorptive capacity refers to the individual's ability to utilize available knowledge. Absorptive ca- pacity is a function of the individual's preexisting stock of knowledge and is heavily dependent on tacit knowledge (Szulanski 1996). The more complex and ambiguous the knowledge, the more tacit and explicit knowledge must exist together for knowledge to be usable (Schultze 2000). For example, Nambisan et al. (1999) examine organizational mechanisms for enhancing user-based innovations for information technology. In their review and conclusions, they note that users must have a combination of both explicit knowledge (e.g., an understanding of available technologies and their basic capabilities) and tacit knowledge (e.g., context dependent knowledge perhaps gained from association with the technology vendors) for effective development of new technology application ideas. Thus, the ability to make use of even quite explicit knowledge may be dependent on more tacit elements.

\section{Proposition 6: The transition of poten- tial team knowledge to usable knowledge is positively moderated by individual absorptive capacity.}

\begin{abstract}
Absorptive capacity can be enhanced through the social transfer of tacit knowledge from one individual to another (Nonaka 1994). Thus, for the team to be able to utilize members' knowledge, all members of the team must have some degree of related tacit knowledge. Because tacit knowledge transfers among team members through social interaction, virtual teamwork may impede that social interaction, thus the transfer of necessary tacit knowledge as represented by the shaded arrow from individual knowledge to absorptive capacity in Figure 2. A flavor for this is found in a quote from a product organization manager experienced in distributed project work (Orlikowski 2002, p. 259):
\end{abstract}

These face-to-face meetings are very effective for letting us hear about the other subprojects. So we see what their risks and their problems are, to see if that may apply to us....It is also very effective in building relations between the subprojects, in case we need a favor, or something like that. That is helpful. 
We believe that virtualness has a direct effect on the level of absorptive capacity among team members. Over time, the members' further development of absorptive capacity may be hampered because their ability to develop new tacit knowledge is constrained. While it is possible that members of more virtual teams could develop absorptive capacity from collocated others who are not on the team, the development of absorptive capacity would be relatively lower and less specific to the team tasks than that of an equivalent, but less virtual, team. As such, we propose

\section{Proposition 7: To the extent that more virtual work limits the social interaction of the team members, virtual teamwork will reduce the absorptive capacity of team members.}

Access to communities of practice also influences individuals' ability to transform potential team knowledge into usable knowledge. Over time, the interactions among individuals develops into communities of practice (Leonard and Sensiper 1998, p. 126), which enable the further transfer of both explicit and tacit knowledge and provides the learning context needed to enact potential team knowledge. Brown and Duguid (2000) note that

practices in common...allow people to form social networks along which knowledge about that practice can both travel rapidly and be assimilated readily ( $p$. 141).

These social networks may or may not be part of the team structure (thus our inclusion in the individual knowledge section of the model: individuals may bring with them memberships in various communities of practice). Communities of practice are broader than transactive memory, the group level construct we will discuss below, in that they extend beyond the team. The communities are fluid, interpretive, and often incorporate people from outside the team or organization (Brown and Duguid 1991). The knowledge is more about a common language or point of view than about particular rules. We suggest that the team can utilize the potential team knowledge to the extent that team members are also members of the communities of practice relevant to the team's task.

\section{Proposition 8: The transition of poten- tial team knowledge to usable knowledge is positively moderated by individuals' connections to relevant communities of practice.}

Communities of practice develop when there are ample opportunities for informal contact. Informal, voluntary users' groups focus on sharing of relevant experiences that enable acquisition or transfer of tacit knowledge about technology applications (Nambisan et al. 1999). An environment of frequent and intensive interactions among members forms a high-density field of interactions (Nonaka and Takeuchi 1995). A certain level of personal intimacy (Leonard and Sensiper 1998) is necessary to establish communication of tacit knowledge. Transfers of best practices in firms were significantly impeded when arduous relationships between the sources and recipients reduced the transfer of both tacit and explicit knowledge (Szulanski 1996).

This highlights the possibility of two dynamics related to communities of practice. More virtual teams, by virtue of their members' more diverse social connections, may have access to a wider range of communities of practice outside of the team. However, the arrow in Figure 2 relating individual knowledge to communities of practice reflects the notion that while access to communities of practice may be greater in more virtual teams, team virtualness may impede informal interaction among members. This suggests that there is less possibility that tacit knowledge from relevant communities of practice will transfer from team member to team member in more virtual teams.

Proposition 9a: More virtual teams will have greater access to communities of practice than will less virtual teams.

Proposition 9b: Tacit knowledge from members' links to communities of prac- 
tice are less likely to be disseminated within more virtual teams than they are within less virtual teams.

The above discussion focused on individual knowledge that is brought to the team, how that knowledge is affected by more virtual work, and the role that moderating factors play at the individual level of analysis as we look at the transition from potential team knowledge to usable knowledge.

\section{Transactive Memory and Team Synergy}

Argote (1999) describes team learning as a process where members share their own knowledge, generate new knowledge, and evaluate and combine this knowledge. The ability to turn tacit and explicit individual knowledge into team-level knowledge should be associated with the development of transactive memory (e.g.,Wegner 1986). Recall that potential team knowledge resides differentially among the members of the team. Groups need a transactive memory system to help them effectively apply potential knowledge toward performance (e.g., Liang et al. 1995). Argote (1999) notes that group learning combines knowledge that individual members bring to the group with the knowledge developed by these individuals within the group. Levine and Moreland (1991, cited in Argote 1993) describe the kinds of knowledge that groups acquire: knowledge about the group (culture, structure, norms); knowledge of each other (who is good at which tasks); and knowledge about the work (what kinds of work the group does, how it should be done). The development of transactive memory (Wegner 1986, 1995) and its importance to group performance is an underlying theme in much of this work.

Transactive memory is a shared system for encoding, storing, and retrieving knowledge available to the group. More specifically, transactive memory is comprised of three components: directory updating - the process whereby members of the group come to learn where knowledge is likely to be stored amongst group members (who knows what); information allocation-the process of distributing knowledge to the member(s) whose expertise is best suited for its storage; and retrieval coordination-the process of retrieving knowledge most effectively given knowledge of expertise distribution in the group (Wegner 1995).

Transactive memory moderates the transformation of potential team knowledge to usable knowledge by allowing the members to be more efficient in their processes (Liang et al. 1995; Moreland et al. 1998; Wegner 1986, 1995). Potential team knowledge is more directly transformed into usable knowledge when transactive memory forms within the group.

\section{Proposition 10: The transfer of poten- tial team knowledge to usable team knowledge will be positively moderated by team transactive memory.}

Hollingshead (1998) argues that shared experiences, common language, and joint decision making facilitate the development of transactive memory. Argote, Moreland, and their colleagues have shown that groups who train together on the task they are to perform develop transactive memory relevant to the task and so are able to outperform teams who train apart or who do not train together on their given task. These conditions for the development of transactive memory would seem to argue against effective transactive memory development in more virtual groups. We agree that transactive memory development may be more difficult in situations where groups work apart and are located in different environments. However, we also believe that technology or organizational systems may be able to support transactive memory development in such a way as to mitigate the difficulties otherwise experienced.

Moreland and Myaskovsky (2000) experimentally examined groups who were provided with exogenously generated evaluations of members' levels of performance. These groups were able to perform as effectively as groups who trained together on the task. We believe this is support for the idea that transactive memory can be artificially created through technologies or other 
organizational systems that supply the building blocks of transactive memory: directory updating, information allocation, and retrieval coordination.

\section{Proposition 11a: More virtual teams will have lower transactive memory devel- opment than less virtual teams.}

\begin{abstract}
Proposition 11b: The expected overall negative relationship between teams working more virtually and the development of transactive memory will be mitigated to the extent that technologies or organizational systems are used to support transactive memory development.
\end{abstract}

The transformation of potential team knowledge to usable knowledge is also moderated by team synergy (e.g., Watson et al. 1991). Synergy speaks to the generation of additional knowledge once the members are in the team. This is the knowledge behind the idea that teams are greater than the sum of their parts. Whereas transactive memory speaks to the efficient use of the information brought to the team (and eventually, that knowledge developed by the team), synergistic knowledge is developed though the team's interaction. Synergistic knowledge is defined as knowledge created within the team-beyond the potential knowledge initially held by the team's individuals (emergent knowledge; Argote 1999). For example, two members each know one, different way to solve a problem (information that could be stored as an aspect of transactive memory); yet together they are able to develop a third, new solution (synergy). Popular presentations (Corning 1986), as well as experimental research (Reagan-Cirincione 1994; Watson et al. 1991; Weldon and Bellinger 1997), have shown that team performance can exceed that of the average performance of the team's members, and often that of the team's most proficient member. Thus, the moderating relationship between potential team knowledge and usable knowledge is expected to be positive.

Proposition 12: The transition of potential team knowledge to usable knowledge is positively moderated by the level of synergy in the team.
We have said that synergistic knowledge is that developed once the team is together-beyond the knowledge that individual members bring to the team. However, the goal of the teams' knowledge development can be either convergent (e.g., decision making), or divergent (i.e., idea generation). DeSanctis and Monge (1999) provide a concise review of the recent literature, noting that computer-mediated teams are more effective than face-to-face teams when working on divergent tasks, and less so on convergent tasks. To understand how this plays out in more virtual teams, we must acknowledge that teams may have control of their task and technology combinations, as suggested by either a sociotechnical (e.g., Trist and Murray 1993) or adaptive structuration perspective (e.g., DeSanctis and Poole 1994). For divergent tasks, more virtual teams may be at an advantage for synergy creation, while for convergent tasks, more traditional teams would be more likely to be effective. However, given that most teams are hybrid (using a combination of computer-mediated and face-to-face communication), ideally teams would choose a taskmedium combination that would support their goals. That is,

\section{Proposition 13: The relationship between team virtualness and synergy will be moderated by the degree of match between team task and techno- logy use.}

\section{Organizational Knowledge: Technology, Structures, and Routines}

Earlier we provided a brief description of the components of organizational knowledge, the final link in our model. Many authors suggest that as knowledge is enacted in organizations, it is captured through the organization's technologies, structures, and routines (Leonard and Sensiper 1998). We believe that knowledge can be useful to organizations while it resides in the organization's individuals and teams. However, if others hold that knowledge, then it must be captured in a 
repository that is not dependent on individuals before it can be of value to the organization (Levitt and March 1988). Our perspective is consistent with that of Huber (1991) and his colleagues, who describe three repositories for information and knowledge that organizations have acquired and retained: the minds of organizational members, organizational records (hardcopy or electronic), and the embodiment of the organization in its equipment, procedures, routines, and physical layout (Huber et al. 1998). The technology, structure, and routines of the organization embody the past actions of the organization and provide the context and foundation for knowledge within the individuals and teams. Change or learning in organizations comes from the knowledge that individuals bring into the organization and/or that teams create through the combination and synergy of knowledge held within the team. We note this on the bottom of Figure 2 as the recursive flow from usable knowledge to organizational standards and routines, through to the initial knowledge types that feed into potential team knowledge.

\section{Discussion}

Figure 2 illustrates a way of thinking about the forms of knowledge and their transfer within teams and the organization. Figure 2 also makes it explicit that virtualness impacts knowledge transfer at three key points: (1) transfer and development of knowledge among team members; (2) formation of absorptive capacity and community of practice; and (3) formation of transactive memory and synergy.

Having worked through the knowledge transfer processes depicted in Figure 2, it is now time to turn our attention to the implications of this model for the relationship between individuals and their organizations. Is information technology, by way of its enabling of more virtual teams, a jealous mistress? Does information technology in virtual teams increase the transformation of tacit knowledge to explicit, while at the same time reducing the development of new, individually held tacit knowledge? Do such dynamics increase value to the organization while decreasing value to the individual? We think the answers may be yes, unless certain safeguards are put in place. Without such safeguards, we believe that organizations may achieve short-term gains by this symmetry, although in the long term organizations will also lose as knowledge generation and the resulting transformation slows.

\section{Knowledge in Organizations: Is Information Technology a Jealous Mistress?}

Effective organizational strategies include those where the organization possesses scarce knowledge, which is not easily transferred or replicated (Grant 1991). A corollary of this is that it is risky for this knowledge to dwell within an individual employee, or in a form that can easily leak across a firm's boundaries (Liebeskind 1997). Of respondents to a KPMG (1998) survey, 49 percent said they had lost best practice knowledge as a result of an employee leaving the organization.

On the other hand, an effective individual strategy is one where the individual maintains his or her value by retaining just such unique knowledge stores as the firm's strategy strives to capture (Burt 1992): by the individual filling a "structural hole." The individual benefits from retaining knowledge as tacit knowledge that cannot easily be assimilated by others. Sharing of this intangible knowledge allows the person sharing it to be viewed as value adding (Schultze 2000). Thus, if the individual allows his or her tacit knowledge to be converted into explicit knowledge, he/she loses the benefit of retaining that knowledge; but if that tacit knowledge is used by the individual within the team (remaining tacit), the tacit knowledge accrues a special status to its holder.

We propose that information technology may play the role of a jealous mistress. As individuals function in contexts enabled by information technology (such as in the context of more virtual teams), more of their knowledge may become 
embodied in information systems or organizational systems more broadly (e.g., Zuboff 1988). As discussed above, in the case of teams working across a range of traditional (face-to-face), hybrid (both face-to-face and electronically supported communication, documentation, and decision support), and more virtual (largely electronically mediated and supported) settings, we propose that the distribution and form of knowledge may vary. Specifically, over time more virtual settings may be associated with a greater focus on explicit knowledge (a possible benefit for the organization), while the relative amounts of unique, tacit knowledge held by individuals may decrease.

Thus, information technology is a jealous mistress to the extent that technologically enabled settings are more likely to create opportunities to intentionally, or even unintentionally, move individual level knowledge into organizationally accessible repositories. Simultaneously, the same systems significantly hamper the ability of team members to create new, tacit knowledge through team interaction. When this happens, the particular individual is no longer so unique or valuable a contributor within the organization. Thus, the relationship between the individual and the organization may be changed by information technology. If ignored, this cycle may result in a short-term benefit for the organization, only to be replaced by a rather serious and consequential long-term cost.

\section{Organizational Implications}

In the long term, organizations would appear to have two choices. In a Machiavellian world, organizations might develop systems where they quickly turn over employees after any unique knowledge has been stripped away (simulations in March [1991] describe such a process). Alternatively, information technologies and the organizational systems within which they exist could be managed to improve the transmission of more tacit knowledge (e.g., Carlson and Zmud 1999), or the individual development of tacit knowledge based on more broadly available explicit knowledge. Richer media facilitating the communi- cation of intuition through personal, nonverbal, and other rich communication forms would characterize these systems. These systems may support the levels of personal experimentation and learning-by-doing that are necessary to transfer tacit knowledge among individuals (Sternberg and Frensch 1993).

\section{Future Research}

Through further research, the field should be able to identify the limiting conditions for effective learning and knowledge transfer across the range of traditional, hybrid, and virtual teams. Such conditions may include the stability of group membership (e.g., Gruenfeld et al. 2000), magnitude of geographical dispersion (e.g., Festinger et al. 1950), types of technological support, and/or timing of face-to-face interaction (Mannix et al. in press). Observations such as those presented here serve as a starting point for critical organizational and technological design decisions.

The model and propositions we have suggested are potentially testable. In Table 1, we catalogue the constructs and assessments necessary to test our model. While there are good measures of some of the antecedent and moderator variables in our model, other measures need to be modified or further developed. For example, the primary team characteristic we are interested in is virtualness and in this case there are some extant survey measures (e.g., Griffith et al. 2003; Watson-Manheim et al. 2002). Proposition 4a suggests that media richness must be considered to understand how teams may form their own structuration of the media to meet team communication needs, and here too there are extant measures. We suggest that perceived social influence as measured by Carlson and Zmud (1999), as well as the expanded survey of perceived media richness (Ferry et al. 2001), can be used to assess the social context of the virtual technology used by the team. Propositions $5 \mathrm{a}$ and $5 \mathrm{~b}$ suggest that task interdependence is also an important moderator of the relationship between individual and team knowledge. As shown in Table 1, measures for these constructs also exist. 


\section{Table 1. Operationalization of Constructs to Test the Theoretical Model}

\begin{tabular}{|c|c|c|}
\hline CONSTRUCT & ASSESSMENT & REFERENCES \\
\hline
\end{tabular}

Team Characteristics

- Team Virtualness

Time spent interacting with team mem- Griffith et al. (2003) bers via various media and face-toface, location

- Task Interdependence Task, goal and outcome interdependence

Campion et al. (1993)

- Media Richness

Multiple channels, immediacy of feed-

Carlson and Zmud (1999) back, language variety, personalness Ferry et al. (2001)

Individual Knowledge Types

- Explicit, implicit and tacit

Extent to which individuals rely on codified knowledge, versus knowledge which could be codified but has been made automatic by practice, versus knowledge gained through direct experience

Social Knowledge Types

- Objectified, collective and shared understanding

Extent to which team has objectified or Measures to be developed collective knowledge or relies on shared understandings.

Individual Moderators

- Absorptive Capacity Recipient capacity to utilize information

Adaptation of Szulanski (1996)

- Communities of Practice

Survey assessing external and internal sources of communities of practice

Measures to be developed (paradigms, practice norms, etc.)

Team Moderators

- Transactive Memory

Specialization, credibility, and Lewis (in press) coordination

- Synergy Synergistic group processes

Watson and Michaelsen (1988)

Knowledge Utilization

- Ratings of knowledge produced by the team

Ratings by horizontal and vertical teams

Adaptation of Schulz (2001) of knowledge outflow from the team

- Evidence of knowledge generation within the Ratings by supervisors of the production of new, unique, and useful team knowledge by the team

Adaptation of measures of creative output. Amabile (1982) 
Perhaps the least well measured, and most difficult to measure, constructs are those related to types of knowledge. Because knowledge is potentially infinite, it is impossible to measure how much or what relative proportion of knowledge a team possesses. Much of the existing research on knowledge transfer has been conducted at the organizational level of analysis. To test our model, better measures of knowledge transfer at the individual and group level of analysis must be developed.

Extant work provides a foundation for this development. The empirical research on tacit knowledge at the individual level has focused on tacit knowledge as an element of general intelligence (Sternberg and Hedlund 2002), or as situational judgment (Chan and Schmitt 2002). The measures used in this research have been very task specific (see Sternberg and Hedlund 2002) and so would be difficult to apply to a more general model test. However, researchers have been able to tap knowledge constructs by focusing on how one gains knowledge (Berry 1987 ) and how knowledge is transferred (Schulz 2001). Additionally, recent refinements to the conceptualization of tacit and explicit knowledge (Castillo 2002; Smith 2001) provide a rich framework to develop broader survey approaches. We thus propose that surveys could be developed to ask team members the extent to which they rely on codified knowledge versus implicit knowledge made automatic through practice or routines versus knowledge gained through experience or formed as a shared understanding by working together. Perhaps the first research task is to construct and validate such measures of knowledge sources.

In addition to surveying team members about the types and sources of knowledge they use, researchers could attempt to assess the knowledge outputs of the team. While it may not be possible to assess the total potential team knowledge in all but the most constrained settings, we suggest that usable knowledge can be indirectly assessed by looking at the knowledge outputs of the team in much the same way as creativity researchers have assessed individual and team creative output (Amabile 1982) or team knowledge output (Schulz 2001).

Our model also suggests individual and team moderators. Prior work has successfully constructed and validated a survey measure of transactive memory (Lewis in press) and synergistic group processes (Watson and Michaelsen 1988). Szulanski (1996) has measured individual absorptive capacity and these measures could be adapted for our purposes. Communities of practice have not been measured at the individual level of analysis. However, researchers could use concepts about the extent to which the team members share paradigms and practice norms as explicated by Brown and Duguid (2000), along with the source of these practices (professions or team peers) to formulate survey measures to tap the idea of communities of practice. Overall, there is a solid foundation to build these next empirical steps.

\section{Conclusion}

Organizations are under constant pressure to make more with less. Two common approaches are to seek synergies by structuring work into team processes, and to be more efficient in the use of organizational knowledge. Here, we consider the transformation of knowledge from individuals to teams and organizations. We consider this transformation across the range of more and less virtual teams-from more traditional teams that work in face-to-face settings to more virtual teams that spend less time together and are more likely to use technological support in their work (e.g., Griffith and Neale 2001).

We construct a theoretical model suggesting that teams in more virtual settings will process their knowledge such that eventually they will focus on, and be better able to transfer, explicit rather than tacit knowledge. This focus may unfortunately reduce the team's ability to utilize much of the available knowledge (i.e., tacit knowledge) in the team. Similarly, it is unlikely that much of the knowledge available through the individuals will be 
effectively converted to organizational knowledge. Organizational knowledge is dependent on more tacit processes, such as enactment, to be transferred into the technology, structures, and routines that retain knowledge for future organizational use. We suggest a variety of organizational actions which may mitigate these limitations to knowledge transfer in more virtual teams, including

- verbalization of rules, terminology, and descriptions

- experience-building opportunities with team members, technology, and task

- access to tools that support highly interdependent work

- development of communities of practice

- development of strategies and technologies that support transactive memory

- evelopment of strategies and technologies that support the transfer of tacit knowledge

- focus on continued development of individuallevel tacit knowledge

Without such actions, the combination of information technology and more virtual work may change the dynamics of knowledge transfer in organizations in unintended ways.

\section{Acknowledgments}

We thank Russell Coff, Mariann Jelinek, Gregory Northcraft, Albert Segars, and Carol Saunders for their thoughtful consideration and comments on earlier drafts.

\section{References}

Amabile, T. M. "Social-Psychology of Creativity: A Consensual Assessment Technique," Journal of Personality and Social Psychology (43:5), 1982, pp. 997-1013.

Ancona, D. G., and Caldwell, D. "Demography and Design: Predictors of Product Team Performance," Organization Science (3:3), 1992, pp. 321-341.
Argote, L. "Group and Organizational Learning Curves: Individual, System and Environmental Components," British Journal of Social Psychology (32), 1993, pp. 31-51.

Argote, L. Organizational Learning: Creating, Retaining and Transferring Knowledge, Kluwer Academic Publishers, Boston, 1999.

Barley, S. R. "Technology as an Occasion for Structuring: Evidence from Observations of CT Scanners and the Social Order of Radiology Departments," Administrative Science Quarterly (31:1), 1986, pp. 78-108.

Berman, S. L., Down, J., and Hill, C. W. L. "Tacit Knowledge as a Source of Competitive Advantage in the National Basketball Association," Academy of Management Journal (45:1), 2002, pp. 13-31.

Berry, D. C. "The Problem of Implicit Knowledge," Expert Systems (4:3), 1987, pp. 144-150.

Boutellier, R., Gassmann, O., Macho, H., and Roux, M. "Management of Dispersed Product Development Teams: The Role of Information Technologies," R\&D Management(28:1), 1998, pp. 13-25.

Brown, J. S., and Duguid, P. "Organizational Learning and Communities-of-Practice: Toward a Unified View of Working, Learning, and Innovation," Organization Science (2:1), 1991, pp. 40-57.

Brown, J. S., and Duguid, P. The Social Life of Information, Harvard Business School Press, Boston, 2000.

Burt, R. S. Structural Holes: The Social Structure of Competition, Harvard University Press, Cambridge, MA, 1992.

Campion, M. A., Medsker, G. J., and Higgs, A. C. "Relations between Work Group Characteristics and Effectiveness: Implications for Designing Effective Work Groups," Personnel Psychology (46:4), 1993, pp. 823-850.

Carlson, J. R., and Zmud, R. W. "Channel Expansion Theory and the Experiential Nature of Media Richness Perceptions," Academy of Management Journal (42:2), 1999, pp. 153170.

Castillo, J. "A Note on the Concept of Tacit Knowledge," Journal of Management Inquiry (11:1), 2002, pp. 46-57. 
Chan, D., and Schmitt, N. "Situational Judgment and Job Performance," Human Performance (15:3), 2002, pp. 233-254.

Cohen, W. M., and Levinthal, D. A. "Absorptive Capacity: A New Perspective on Learning and Innovation," Administrative Science Quarterly (35:1), 1990, pp. 128-152.

Corning, P. Winning with Synergy, Harper and Row, New York, 1986.

Davenport, T. H., and Pearlson, K. "Two Cheers for the Virtual Office," Sloan Management Review (39:4), Summer 1998, pp. 51-65.

DeSanctis, G., and Monge, P. "Introduction to the Special Issue: Communication Processes for Virtual Organizations," Organization Science (10:6), 1999, pp. 693-703.

DeSanctis, G., and Poole, M. S. "Capturing the Complexity in Advanced Technology Use: Adaptive Structuration Theory," Organization Science (5:2), 1994, pp. 121-147.

DeSanctis, G., Poole, M. S., and Dickson, G. W. "Teams and Technology: Interactions Over Time," in Research on Managing Groups and Teams: Technology (Volume 3), M. A. Neale, E. A. Mannix, and T. L. Griffith (eds.), JAI Press, Stamford, CT, 2000.

Ferry, D. L., Kydd, C. T., and Sawyer, J. E. "Measuring Facets of Media Richness," Journal of Computer Information Systems (41:4), 2001, pp. 69-78.

Festinger, L., Schachter, S., and Back, K. W. Social Pressures in Informal Groups: A Study of Human Factors in Housing, Harper Brothers, New York, 1950.

Gammack, J. G., and Yong, R. M. "Psychological Techniques for Eliciting Expert Knowledge," in Research and Development in Expert Systems, M. A. Bramer (ed.), Cambridge University Press, Cambridge, England, 1985.

Goins, S., and Mannix, E. "Self-Selection and its Impact on Team Diversity and Performance," Performance Improvement Quarterly (12:1), 1999, pp. 127-147.

Goodman, P. S., and Darr, E. D. "ComputerAided Systems and Communities: Mechanisms for Organizational Learning in Distributed Environments," MIS Quarterly (22:4), 1998, pp. 417-440.
Granovetter, M. "The Strength of Weak Ties," American Journal of Sociology (78:6), 1973, pp. 1360-1379.

Grant, R. M. "The Resource-based Theory of Competitive Advantage: Implications for Strategy Formulation," California Management Review (33:3), 1991, pp. 114-135.

Griffith, T. L. "Technology Features as Triggers for Sensemaking," Academy of Management Review (24:3), 1999, pp. 472-488.

Griffith, T. L., Mannix, E. A., and Neale, M. A. "Conflict in Virtual Teams," in Virtual Teams That Work, S. G. Cohen and C. B. Gibson (eds.), Jossey-Bass, San Francisco, 2003, pp. 335-352.

Griffith, T. L., and Neale, M. A. "Information Processing in Traditional, Hybrid, and Virtual Teams: From Nascent Knowledge to Transactive Memory," in Research in Organizational Behavior (Volume 23), B. M. Staw and R. I. Sutton (eds.), JAI Press, Stamford, CT, 2001, pp. 379-421.

Griffith, T. L., and Northcraft, G. B. "Distinguishing between the Forest and the Trees: Media, Features, and Methodology in Electronic Communication Research," Organization Science (5:2), 1994, pp. 272-285.

Gruenfeld, D. H., Martorana, P. V., and Fan, E. T. "What Do Groups Learn from Their Worldliest Members? Direct and Indirect Influence in Dynamic Teams," Organizational Behavior and Human Decision Processes (82:1), 2000, pp. 45-59.

Hollingshead, A. B. "Cognitive Interdependence and Convergent Expectations in Transactive Memory," Journal of Personality and Social Psychology (81:6), 2001, pp. 1080-1089.

Hollingshead, A. B. "Retrieval Processes in Transactive Memory Systems," Journal of Personality and Social Psychology (74:3), 1998, pp. 659-671.

Huber, G. P. “Organizational Learning: The Contributing Processes and the Literatures," Organization Science (2:1), 1991, pp. 88-115. Huber, G. P., Davenport, T. H., and King, D. R. "Perspectives on Organizational Memory," paper presented at the $31^{\text {st }}$ Annual Hawaii International Conference on System Sciences, 1998. 
Janz, B. D., Colquitt, J. A., and Noe, R. A. "Knowledge Worker Team Effectiveness: The Role of Autonomy, Interdependence, Team Development, and Contextual Support Variables," Personnel Psychology (50:4), 1997, pp. 877-904.

Jehn, K. A., Northcraft, G. B., and Neale, M. A. "Why Differences Make a Difference: A Field Study of Diversity, Conflict, and Performance in Workgroups," Administrative Science Quarterly (44:4), 1999, pp. 741-763.

KPMG. Knowledge Management: Research Report. KPMG Management Consulting, London, 1998.

Kogut, B., and Zander, U. "Knowledge of the Firm, Combinative Capabilities, and the Replication of Technology," Organization Science (3:3), 1992, pp. 383-397.

Leavitt, H. J. "The Old Days, Hot Groups and Manager's Lib," Administrative Science Quarterly (41:2), 1996, pp. 288-300.

Leonard, D., and Sensiper, S. "The Role of Tacit Knowledge in Group Innovation," California Management Review (40:3), 1998, pp. 112132.

Levine, J. M., and Moreland, R. L. "Culture and Socialization in Work Groups," in Perspectives on Socially Shared Cognition, L. Resnick, J. Levine, S. Behrend (eds.), American Psychological Association, Washington, DC, 1991.

Levitt, B., and March, J. "Organizational Learning," Annual Review of Sociology (14), 1988, pp. 319-340.

Lewis, K. "Measuring Transactive Memory Systems in the Field: Scale Development and Validation," Journal of Applied Psychology, in press.

Liang, D. W., Moreland, R., and Argote, L. “Group versus Individual Training and Group Performance: The Mediating Role of Transactive Memory," Personality and Social Psychology Bulletin (21:4), 1995, pp. 384-393.

Liebeskind, J. P. "Keeping Organizational Secrets: Protective Institutional Mechanisms and Their Costs," Industrial and Corporate Change (6:3), 1997, pp. 623-663.

Liebeskind, J. P. "Knowledge, Strategy, and the Theory of the Firm," Strategic Management Journal (17:10), 1996, pp. 93-107.
Majchrzak, A., Rice, R. E., King, N., Malhotra, A., and $\mathrm{Ba}, \mathrm{S}$. "Computer-Mediated Inter-Organizational Knowledge-Sharing: Insights from a Virtual Team Innovating Using a Collaborative Tool," Information Resources Management Journal (13:1), 2000, pp. 44-53.

Mannix, E., Neale, M. A., and Blount-Lyon, S. (eds.). Research on Managing Groups and Teams: Time in Groups, Elsevier, Amsterdam, in press.

March, J. G. "Exploration and Exploitation in Organizational Learning," Organization Science (2:1), 1991, pp. 71-87.

McGrath, J. E., and Berdahl, J. L. "Groups, Technology, and Time: Use of Computers for Collaborative Work," in Applications of Theory and Research on Groups to Social Issues (Volume 4), R. S. Tindale, L. Heath, J. Edwards, E. J. Posvoc, F. B. Bryant, Y. SuarezBalcazar, E. Henderson-King, and J. Myers (eds.), Plenum Press, New York, 1998, pp. 205-228.

Moreland, R. L., Argote, L., and Krishnan, R. "Training People to Work in Groups," in Applications of Theory and Research on Groups to Social Issues (Volume 4), R. S. Tindale, L. Heath, J. Edwards, E. J. Posvoc, F. B. Bryant, Y. Suarez-Balcazar, E. HendersonKing, and J. Myers (eds.), Plenum Press, New York, 1998, pp. 37-60.

Moreland, R. L., and Myaskovsky, L. "Explaining the Performance Benefits of Group Training: Transactive Memory or Improved Communication?," Organizational Behavior and Human Decision Processes (82:1), 2000, pp. 117-133.

Nambisan, S., Agarwal, R., and Tanniru, M. “Organizational Mechanisms for Enhancing User Innovativeness in Information Technology," MIS Quarterly (23:3), 1999, pp. 365-395. Nonaka, I. "A Dynamic Theory of Organizational Knowledge Creation," Organization Science (5:1), 1994, pp. 14-37.

Nonaka, I., and Nishiguchi, T. Knowledge Emergence: Social, Technical, and Evolutionary Dimensions of Knowledge Creation, Oxford University Press, New York, 2001. 
Nonaka, I., and Takeuchi, H. The KnowledgeCreating Company, Oxford University Press, New York, 1995.

Olson, J. R., and Rueter, H. H. "Extracting Expertise from Experts: Methods for Knowledge Acquisition," Expert Systems (4:3), 1987, pp. 152-168.

Orlikowski, W. J. "Knowing in Practice: Enacting a Collective Capability in Distributed Organizing," Organization Science (13:3), 2002, pp. 249-273.

Pfeffer, J., and Sutton, R. I. "The Smart-Talk Trap," Harvard Business Review (77:3), 1999, pp. 143-142.

Polanyi, M. The Tacit Dimension, Doubleday, New York, 1966.

Reagan-Cirincione, P. "Improving the Accuracy of Group Judgment: A Process Intervention Combining Group Facilitation, Social Judgment Analysis, and Information Technology," Organizational Behavior and Human Decision Processes (58:2), 1994, pp. 246-270.

Sawyer, J. E. "Effects of Risk and Ambiguity on Judgments of Contingency Relations and Behavioral Resource Allocation Decisions," Organizational Behavior and Human Development Processes (45:1), 1990, pp. 85-110.

Sawyer, J. E. "Hypothesis Sampling, Construction, or Adjustment: How are Inferences about Nonlinear Monotonic Contingencies Developed?," Organizational Behavior and Human Decision Processes (49:1), 1991, pp. 124-150.

Schultze, U. "A Confessional Account of an Ethnography About Knowledge Work," MIS Quarterly (24:1), 2000, pp. 3-41.

Schulz, M. "The Uncertain Relevance of Newness: Organizational Learning and Knowledge Flows," Academy of Management Journal (44:4), 2001, pp. 661-681.

Smith, E. A. "The Role of Tacit and Explicit Knowledge in the Workplace. Journal of Knowledge Management (5:4), 2001, pp. 311321.

Spender, J. C. "Making Knowledge the Basis of a Dynamic Theory of the Firm," Strategic Management Journal (17:2), Winter 1996, pp. 45-62.
Starbuck, W. H., and Milliken, F. J. "Executives' Perceptual Filters: What They Notice and How They Make Sense," in The Executive Effect: Concepts and Methods for Studying Top Managers, D. C. Hambrick (ed.), JAI Press, Greenwich, CT, 1988.

Sternberg, R. J., and Frensch, P. A. "Mechanisms of Transfer," in Transfer on Trial: Intelligence, Cognition, and Instruction, D. K. Detterman and R. J. Sternberg (eds.), Ablex Publishing, Norwood, NJ, 1993, pp. 25-38.

Sternberg, R. J., and Hedlund, J. "Practical Intelligence, G, and Work Psychology," Human Performance (15:2), 2002, pp. 143-159.

Swartout, W. R., and Smoliar, S. "On Making Expert Systems More Like Experts," Expert Systems (4:3), 1987, pp. 196-207.

Szulanski, G. "Exploring Internal Stickiness: Impediments to the Transfer of Best Practices Within the Firm," Strategic Management Journal (17:10), 1996, pp. 27-43.

Teachman, J. D. "Analysis of Population Diversity," Sociological Methods and Research (8), 1980, pp. 341-362.

Tidwell, L. C., and Walther, J. B. "ComputerMediated Communication Effects on Disclosure, Impressions, and Interpersonal Evaluations," Human Communication Research (28:3), 2002, pp. 317-348.

Trist, E., and Murray, H. (eds.). The SocioTechnical Perspective (Volume II), University of Pennsylvania Press, Philadelphia, 1993.

Tschan, F., and von Cranach, M. "Group Structure, Process and Outcome," in Handbook of Work Group Psychology, M. E. West (ed.), John Wiley \& Sons, New York, 1996, pp. 95121.Sons.

Venzin, M., von Krogh, G., and Roos, J. "Future Research Into Knowledge Management," in Knowing in Firms, G. von Krogh, J. Roos, D.Kleine (eds.), Sage Publications, Thousand Oaks, CA, 1998, pp. 26-66.

Von Hipple, E. "Sticky Information and the Locus of Problem Solving: Implications for Innovation," Management Science (40:4), 1994, pp. 429-439.

Walsh, J. P., and Ungson, G. R. "Organizational Memory," Academy of Management Review (16:1), 1991, pp. 57-91. 
Watson, W. E., and Michaelsen, L. K. "Group Interaction Behaviors that Affect Performance on an Intellective Task," Group and Organization Studies (13:4), 1988, pp. 495-516.

Watson, W. E., Michaelsen, L. K., and Sharp, W. "Member Competence, Group Interaction, and Group Decision Making: A Longitudinal Study," Journal of Applied Psychology (76:6), 1991, pp. 803-809.

Watson-Manheim, M. B., Chudoba, K. M., and Crowston, K. "Discontinuities and Continuities: A New Way to Understand Virtual Work," Information, Technology, and People (15:3), 2002, pp. 191-209.

Wegner, D. "Transactive Memory: A Contemporary Analysis of the Group Mind," in Theories of Group Behavior, in G. Mullen and G. Goethals (eds.), Springe-Verlag, New York, 1986, pp. 185-208.

Wegner, D. M. "A Computer Network Model of Human Transactive Memory," Social Cognition (13:3), 1995, pp. 319-339.

Weldon, M. S., and Bellinger, K. D. "Collective Memory: Collaborative and Individual Processes in Remembering," Journal of Experimental Psychology: Learning, Memory and Cognition (23), 1997, pp. 1160-1175.

Zander, U., and Kogut, B. "Knowledge and the Speed of the Transfer and Imitation of Organizational Capabilities: An Empirical Test," Organization Science (6:1), 1995, pp. 76-92.

Zuboff, S. In the Age of the Smart Machine, Basic Books, New York, 1988.

\section{About the Authors}

Terri L. Griffith is a professor of Management and Breetwor Fellow in the Leavey School of Business, Santa Clara University. She has also served on the faculties of Washington University and the University of Arizona. Terri received her Ph.D. from Carnegie Mellon University. Her research focuses on the effective use of new technologies, most recently focusing on virtual teams and "negotiated implementation." Her work is published in journals such as Organization Science, Information Systems Research, MIS Quarterly, and the Academy of Management Review. She recently coedited the book, Research on Managing Groups and Teams: Technology (2000, JAI Press) and is a Senior Editor for Organization Science.

John E. Sawyer is Chair of the Department of Business Administration in the Alfred Lerner College of Business \& Economics at the University of Delaware. John received his Ph.D. from the University of Illinois, Champaign. His research focuses on learning and judgment, group decision-making, information sharing and integration in multifunctional groups, and social and contextual influences on creativity and innovation. John's work has been published in Academy of Management Review, Journal of Applied Psychology, Personnel Psychology, Organizational Behavior and Human Decision Processes, Journal of Applied Social Psychology, Journal of Computer Information Systems, Social Justice Research and as chapters in four scholarly books.

Margaret A. Neale is the John G. McCoyBanc One Corporation Professor of Dispute Resolution and Organizations at the Graduate School of Business of Stanford University. In addition, she has served on the faculties of the Eller School of Business at University of Arizona the Kellogg School of Management at Northwestern University since receiving her $\mathrm{Ph}$.D. from the University of Texas in 1982. She has published over 70 refereed articles in the areas of negotiation, decision making, and team performance. 